\title{
Behavioral cues to expand a pain model of the cognitively impaired elderly in long-term care
}

This article was published in the following Dove Press journal:

Clinical Interventions in Aging

29 June 2012

Number of times this article has been viewed

\section{Allison $\mathrm{H}$ Burfield' \\ Thomas TH Wan ${ }^{2}$ \\ Mary Lou Sole ${ }^{3}$ \\ James W Cooper ${ }^{4}$}

'School of Nursing, College of Health and Human Services, University of North Carolina-Charlotte, Charlotte, NC, ${ }^{2}$ Administration, and Medical Education, Doctoral Program in Public Affairs, College of Health and Public Affairs, ${ }^{3}$ College of Nursing, University of Central Florida, Orlando, FL, ${ }^{4}$ College of Pharmacy, University of Georgia, Athens, GA, USA
Correspondence: Allison H Burfield School of Nursing, College of Health and Human Services, University of North Carolina-Charlotte, 920I University City Blvd, Charlotte, NC 28223-000I, USA

$\mathrm{Tel}+\mathrm{I} 7046877966$

Fax +I 7046876017

Email aburfiel@uncc.edu
Background: The purpose of this study was to determine the relationship between hypothesized pain behaviors in the elderly and a measurement model of pain derived from the Minimum Data Set-Resident Assessment Instrument (MDS-RAI) 2.0 items.

Methods: This work included a longitudinal cohort recruited from Medicare-certified longterm care facilities across the United States. MDS data were collected from 52,996 residents (mean age 83.7 years). Structural equation modeling was used to build a measurement model of pain to test correlations between indicators and the fit of the model by cognitive status. The model evaluates the theoretical constructs of pain to improve how pain is assessed and detected within cognitive levels.

Results: Using pain frequency and intensity as the only indicators of pain, the overall prevalence of pain was $31.2 \%$; however, analysis by cognitive status showed that $47.7 \%$ of the intact group was in pain, while only $18.2 \%$ of the severely, $29.4 \%$ of the moderately, and $39.6 \%$ of the mildly cognitively impaired groups were experiencing pain. This finding supports previous research indicating that pain is potentially under-reported in severely cognitively impaired elderly nursing home residents. With adjustments to the measurement model, a revised format containing affective, behavioral, and inferred pain indicates a better fit of the data to include these domains, as a more complete measure of the pain construct.

Conclusion: Pain has a significant effect on quality of life and long-term health outcomes in nursing home residents. Patients most at risk are those with mild to severe cognitive decline, or those unable to report pain verbally. Nursing homes are under great scrutiny to maintain standards of care and provide uniform high-quality care outcomes. Existing data from federally required resident surveys can serve as a valuable tool to identify indicators of pain and trends in care. Great responsibility lies in ensuring pain is included and monitored as a quality measure in long-term care, especially for residents unable to communicate their pain verbally.

Keywords: cognitive impairment, minimum data set, pain behaviors, structural equation modeling, theoretical model

\section{Introduction}

Pain affects $49 \%-83 \%$ of 1.8 million residents living in long-term care facilities in the United States. ${ }^{1-4}$ The outcome of pain and long-term suffering influences psychological, physiological, and social aspects of an individual's life. Chronic pain is associated with symptoms of anxiety and depression, ${ }^{5}$ and can have a serious adverse impact on quality of life. This may result in an inability to sleep, clinical depression, weight loss, disturbances in gait, immune suppression, decreased socialization, increased morbidity, ${ }^{6,7}$ and burgeoning health care costs. ${ }^{5,7,8}$ 
Behavioral and psychosocial factors play an important role in understanding the experience, continuation, and exacerbation of pain. ${ }^{9}$ Individuals display many different behavioral cues, making it difficult for the clinician to comprehend the nursing home resident's needs. Research indicates specific verbal, behavioral, and facial expressions as being representative of pain. ${ }^{10,11}$ Because pain is an individual subjective experience, the complexity of assessing and determining patient pain may increase with cognitive decline. Cognitive decline progressively hampers the individual's ability to anticipate and verbalize pain. ${ }^{12}$ Decades of research indicate pain is poorly assessed and managed in long-term care, especially for those with moderate to severe cognitive impairment. ${ }^{13-18}$ Looking at underlying common characteristics of pain could clarify our understanding of how to measure and better identify pain. Basing detection of pain only on self-reports from patients fails to take into account other indicators that an individual could be expressing.

Research to date lacks a large-scale analysis of pain in long-term care that evaluates a multidimensional construct of pain. The aims of this study were to determine the magnitude of the relationship between pain behaviors and a hypothesized measurement model, to compare theoretical models to existing pain scales, and to examine the construct validity of a pain measurement model. The research question was: can a theoretically derived model of pain aid in detecting pain across all cognition levels?

Multiple smaller-scale studies have evaluated specific pain tools, while recommending additional research using larger samples to increase the generalizability across longterm care settings and to include a more comprehensive analysis of residents most at risk, ie, the severely cognitively impaired. ${ }^{19-23}$ Data from existing nationwide assessment instruments, like the minimum data set (MDS), are a source for evaluating resident pain and other quality initiatives. ${ }^{24}$ The goal of evaluating the dimensions and theoretical constructs of pain is to clarify the validity of measures and the reliability of existing quality indicators from the MDS to be able to detect pain across all cognitive states more accurately.

\section{Significance}

Nursing homes are under great scrutiny for adherence to regulations, quality improvement actions, and public reporting. Stakeholders and researchers have raised concerns about the accuracy, usefulness, and timeliness of reports to describe care in skilled nursing settings. ${ }^{25,26}$ The Joint Commission calls for the close monitoring of pain management in health care settings and evaluates the appropriateness of interventions. ${ }^{27,28}$ The American Health Quality Association reports on health care entities that strive to improve pain management through quality initiatives, and the Centers for Medicare and Medicaid Services encourage ongoing quality improvement in skilled care settings through resident assessment surveys. ${ }^{29}$ Multiple entities are working towards improving care for the elderly, but large-scale research is needed to understand pain behaviors better and ensure pain treatment is effective and ongoing in this population.

Pain has a significant impact on quality of life and outcomes in nursing home residents. Higher levels of comorbidities are reported with severe pain, along with increased depressive symptoms, reduced activity and significant physical effects. ${ }^{30}$ Chronic pain is attributed to diseases like osteoarthritis, cancer, and facture, and neuropathies, with arthritis being the most common. ${ }^{5}$

The study of pain, especially among those residents who are non-communicative, could significantly improve quality of life and the quality of care in nursing homes. ${ }^{31}$ Residents with advanced cognitive decline are at the highest risk for under-treatment because of an inability to verbalize pain. Incorrectly assessing pain leads to a higher incidence of inappropriate medication use, medication side effects, and residents remaining in discomfort. These outcomes fail to apportion health care resources correctly, provide optimal treatment, or resolve the target issue of pain. Using evaluation tools to include a broader context of resident symptoms might help recognize patterns and methods to improve care.

Evaluating aggregate resident care at points over time can highlight successes or failures, and opportunities to improve treatments and outcomes. The integration and mechanisms of information technology/information systems are a helpful tool to combine health care delivery networks to improve resident outcomes. Analysis of data sets can reveal statistical relationships between symptoms, diagnoses, treatments, and outcomes. ${ }^{32}$ Using existing data lessens the difficulties in recruiting and retaining those with increasing inability to assent or comprehend informed consent, offering important insights into resident care.

\section{Background}

Chronic pain in the elderly is most often felt in the feet, legs, back, and major joints. ${ }^{5,33}$ Other types of pain, like headache or visceral aches, are less reported in the elderly. It is estimated at least one in four older individuals suffers with chronic musculoskeletal pain. ${ }^{5}$ Pain is an expression 
of underlying body damage, or peripheral nociceptive stimulation. ${ }^{34,35}$

Pain is often communicated via behaviors. ${ }^{34,36}$ CohenMansfield and Creedon" ${ }^{31}$ define pain behaviors as "observable nonverbal behaviors" to indicate pain to others. Broader definitions include all forms of behaviors displayed by an individual thought to reflect the existence of nociception, including facial expressions, speech, posturing, patterns of medication use, seeking health care intervention, or changes in socialization. ${ }^{35}$ Current studies suggest four clusters of pain behaviors, ie, altered ambulation (gait) or posture, negative affect, facial/audible expressions, and avoidance of activities. ${ }^{37} \mathrm{~A}$ research study of nurses' perceptions of key indicators of pain state that changes in behaviors, repetitive movements, repetitive vocalizations, and physical symptoms are indicative of pain. ${ }^{31}$ Patients with severe dementia do not experience less pain intensity, less painful sites, or have a lower incidence of pain-causing diseases, but pain often goes unassessed and untreated in this population. ${ }^{22}$

The responsiveness of caregivers with regard to intervention is a primary quality of care concern, especially for those institutionalized who rely upon others to interpret and meet their individual needs. A challenge to an understanding of pain is how to differentiate between pain behaviors and the behaviors expected from progression of a disease, such as memory impairment or the inability to communicate needs. If we use unique domains or categories to explain concepts of pain, this can broaden how pain is recognized, especially in the elderly who are cognitively impaired.

\section{Cognition}

Cognition describes how individuals differentiate, encode, store, retrieve, and use information. ${ }^{38}$ The patient's ability to reason, remember, and think describes cognitive status. Cognitive status influences the resident's ability and how he/she communicates with others. A distinction in increasing cognitive decline is how behaviors are communicated. In dementia, wandering may involve an interruption in the individual's ability to follow sequential mental tasks to reach a destination or goal. ${ }^{39}$ The cognitively impaired resident has increased difficulty staying on task and remaining attentive to reach the goal of their activities. Cognitive impairment in conjunction with pain is a significant factor in explaining why certain verbal or nonverbal behaviors occur, and how the clinician could incorrectly interpret cues. Residents with severe cognitive impairment, as with dementia, are at high risk of suffering from pain because of an inability to report their pain verbally. ${ }^{22}$

\section{Affect}

Affect and cognition are thought to be inextricably intertwined; however, some see emotion completely independent of cognition. ${ }^{40}$ Beyond culture-bound expressions of affect, the elderly resident with severe cognitive impairment might have a flattened affect, or have limited verbal capacity with increased moodiness and crying. Affective domains include emotions and feelings. When evaluating mood in nursing home residents, depression may present as generalized aches and pains without a source of injury or disease, while chronic untreated pain may cause depression. ${ }^{41}$ This makes discernment of pain especially difficult in residents with depression. The existence of multiple pain conditions is associated with anxiety and mood disorders across cultures. ${ }^{42}$ Patient mood is an important concept of the pain construct in modeling whether depressed mood is an indicator of pain or a consequence of long-term untreated pain. A seminal work ${ }^{37}$ demonstrated dimensions of pain behaviors including a negative affect and facial expressions of distress consistent with a pain behavior construct. Multiple studies have found significant associations between pain and grimacing. ${ }^{43}$ Research on facial action coding systems has been used to confirm the existence of pain with different levels of cognitive impairment. ${ }^{43,44}$ Findings indicate facial expressions to noxious stimulation are significantly increased in residents with dementia in comparison with cognitively intact residents. ${ }^{45}$ Research of facial expressions indicates that basic primordial expressions occur across cultures, gender, and age, along with learned "socially acceptable" emotions and expressions of mood. If the resident reverts to lower cognitive functioning, making facial expressions instinctive and not a culturally-bound expected reaction, universal expressions of pain could exist. Considering a severe decline in cognition, this might explain facial grimacing as a universal expression of pain.

\section{Behavioral}

A significant determinant of pain behavior is the severity of pain. ${ }^{46}$ Behaviors like verbal complaints/negative vocalizations, sighing, moaning, agitation, crying, grimacing, rapid blinking, shifting/fidgeting, rubbing, resistance, bracing, guarding, and rigidity are common indicators of pain from the literature. ${ }^{47-49}$ Aggressive behaviors in cognitively impaired residents are also indicated as a sign of pain..$^{50}$ Behavioral science indicates that pain behaviors are subject to the same changes and influences which alter actions, as are other types of behaviors. ${ }^{41}$ Much of the research into 
pain describes learned behaviors and operant conditioning as factors involved in continuation of pain behaviors. ${ }^{9,35}$ This assumption might hold true for cognitively intact residents, but is inadequate in explaining repetitive behaviors in the cognitively impaired resident. If pain needs are not being met, what would be the drivers for continuing the behavior?

Behaviors that are not followed by positive consequences but have neutral or adverse responses should diminish and end unwanted behaviors, thus describing the process of operant conditioning. The behavior should be deterred if these actions are not eliciting the desired response. Alternative behaviors would be attempted. The mechanism of operant conditioning does not explain repetitive behaviors, or why pain behaviors would not be eliminated if pain needs were being ignored. This behavioral perspective makes it difficult to attribute behaviors to progression of a disease and those of pain. Essential to an understanding of pain in the elderly are those variables that correlate with actual behaviors, ie, the outcome (consequence) of the behaviors, rather than just isolation of certain affective characteristics.

Disruptive behaviors common in dementia may lead to negative consequences, like continued untreated pain and the use of physical or chemical restraints to control the behavior. ${ }^{51}$ Because one set of signs or behaviors do not uniformly detect pain at all cognitive levels, examining the association of behaviors according to cognitive group would be valuable in advancing research in this field. A comprehensive review ${ }^{37}$ characterizes common problems in attempting to assess pain behaviors accurately as insufficient attention to the attributes of the construct and precision and consistency in the characteristics of the methods of assessment (ie, are the measures comprehensive and reliable?)

\section{Inferred pain}

Pain can be inferred from existing diseases (ie, osteoarthritis, osteoporosis, neuropathies, cancer) that are known to cause pain, and existing pain sites. Having multiple sites of pain causes more severe and disabling effects than having a single site of pain. ${ }^{52}$ Pain assessment tools most commonly ask residents to rate pain and/or report its frequency and intensity. This aspect of pain assessment is essential, because even residents with cognitive impairment should be engaged with eye contact and inquiries into their level of comfort and not discounted as a unreliable source. ${ }^{53,54}$ Additionally, for cognitively impaired residents, direct observation of behaviors is the strongest evidence for ensuring pain is appropriately assessed and treated. ${ }^{55}$ Inferred pain can be another valuable clue to examine and capture pain better. When clinicians use reported pain as the only assessment tool, ie, as a one-dimensional measure, assessments often fall short of being able to detect pain accurately. Application of the Nonverbal Pain Scale to the cognitively impaired person may help increase the accuracy of assessment, detection, and treatment of pain.

\section{Theoretical framework}

The theoretical foundation for this research incorporates the concept of need-driven behaviors and consequences of need-driven, dementia-compromised behaviors to frame a person-centered approach to care ${ }^{39,51,56-59}$ (see Table 1 for definitions). Need-driven, dementia-compromised behaviors are actions displayed to communicate an underlying need. ${ }^{39}$ Optimally, the immediate identification of primary needdriven behaviors would result in an action and resolution to decrease disruptive behaviors. Need-driven behaviors

Table I Theoretical construct definitions ${ }^{38,63}$

\begin{tabular}{|c|c|}
\hline Term & Definition \\
\hline Need-driven behaviors & Expressions of unmet needs or goals \\
\hline $\begin{array}{l}\text { Need-driven dementia compromised } \\
\text { behaviors (NDB) }\end{array}$ & $\begin{array}{l}\text { The most meaningful response a dementia-compromised person can give with the limitations } \\
\text { of the disease process; disruptive behaviors could be the only and base mechanisms of } \\
\text { communication; reflect the interaction of background and proximal factors }\end{array}$ \\
\hline $\begin{array}{l}\text { Consequences of need-driven } \\
\text { dementia-compromised behavior (C-NDB) }\end{array}$ & $\begin{array}{l}\text { Explains the consequences of behavioral symptoms of individuals with dementia; needs are } \\
\text { expressed behaviorally and unmet needs influence additional behavioral cues }\end{array}$ \\
\hline Antecedent & A preceding cause \\
\hline Consequence & $\begin{array}{l}\text { Events/actions that result from inaction of the need or failing to respond appropriately to the } \\
\text { primary need }\end{array}$ \\
\hline Proximal factor & $\begin{array}{l}\text { More changing aspect of a person's physical status or social/physical environment. Proximal } \\
\text { factors are more likely to precipitate NDBs; ie, emotions, light level, noise, staff stability }\end{array}$ \\
\hline Background factor & $\begin{array}{l}\text { Neurological, cognitive, general health or psychosocial factors that produce NDBs; ie, regional } \\
\text { brain involvement, memory/language skills, functional ability, affective state, behavioral } \\
\text { response to stress }\end{array}$ \\
\hline Primary need & Immediate need \\
\hline Secondary need & Needs that may arise from primary needs not being met \\
\hline
\end{tabular}


produce behavioral symptoms and explain how certain interventions could lessen disruptive behaviors. ${ }^{60}$

The concept of dementia-compromised behaviors aids in explaining why continued behaviors are not lessened via the mechanisms of operant conditioning. Pain is one aspect of the framework. The framework is helpful in identifying the primary problem (pain) and developing antecedent and resulting consequences of unmet needs. The initial portion of the theoretical framework is used in this study to identify pain. The remaining structure of the framework is integral to the evaluation of other aspects of the model, including cognitive status and outcomes of untreated pain, like depression, social isolation, comorbidities, effective/non-effective interventions, and the cost-effectiveness of actions taken. ${ }^{61}$

The construct of pain is thought to be multidimensional. ${ }^{36,37}$ How need-driven, dementia-compromised behaviors are expressed is specific to the individual and dependent upon proximal and background factors. Proximal factors are defined as "current situational issues or events", 56,62 varying greatly and dependent upon personal and environmental cues like staffing level or pain with movement. Background factors involve cognitive, psychosocial, neurological, and general health causes. These factors tend to be more constant. Need-driven behaviors aid in explaining why individuals display certain behaviors, especially those with cognitive impairment from dementia. ${ }^{39}$ Need-driven behaviors provide a foundational framework for this study to draw theoretical links between unique indicators obtained from research, state of the science, and clinical practice.

\section{Materials and methods Design and sample}

A secondary analysis of data from the Minimum Data SetResident Assessment Instrument (MDS-RAI) was conducted. A cross-sectional analysis was used to determine pain prevalence. The first-year records of a longitudinal data collection were used for the study. A combined total of 14,435,847 subject observations was reduced to 806,977 (Figure 1) by using annual assessments and applying the inclusion criterion of age $\geq 65$ years. Unconfirmed entry dates into the system were also excluded, resulting in 252,513 subjects. Residents discharged over a 3-year span were dropped, reducing the total to 56,798 . Individuals coded as being comatose were excluded, because the behavioral sections of B-F in the MDS are omitted as per the MDS-RAI instructions. The behavioral indicators evaluated in this research are contained in this section. Residents with schizophrenia were excluded to gain baseline cognitive levels, enabling reduction of the probability of fluctuating mental states due to psychosis. Data cleaning rules yielded a final sample of 52,996 residents to evaluate trends in pain behaviors and associations between cognitive, affective, behavioral, and inferred pain domains.

\section{Instruments}

The MDS is both mandated and the most commonly used resident assessment document in nursing home facilities. The MDS is not a comprehensive assessment, but a preliminary screening tool to help identify potential problems, strengths, and preferences for care. The MDS is a core set of items, definitions, and response categories composed of two parts, ie, the MDS and the resident assessment protocol. The resident assessment protocol is a section of the MDS-RAI providing a problem-oriented framework for additional assessment. ${ }^{63}$ Key items that are problem-specific, trigger assessment for specific conditions. The resident assessment protocol items provide a critical link with care planning. The MDS-RAI 2.0 version has 18 resident assessment protocol items covering the majority of areas addressed by a typical skilled nursing care facility in the care planning process. These items help staff to look for causal or confounding factors that may be reversible. Goals are set to improve deficits where possible, and to maintain and prevent avoidable decline. The current updated MDS is version 3.0 and was introduced after this study was completed.

The MDS has demonstrated good reliability and validity. ${ }^{64-66}$ MDS items have excellent inter-rater and testretest reliability in the key areas of cognition and activities of daily living, with an average weighted kappa of 0.80 . MDS-RAI items met a standard for superb reliability (ie, intraclass correlation of 0.7 or higher) in key categories of functional status, such as cognition, activities of daily living, continence, and diagnoses. ${ }^{67}$

The Cognitive Performance Scale (CPS) ${ }^{68,69}$ was used to assess resident cognitive status. The CPS instrument is a MDS-RAI item scale derived from sections B, C, and G of the resident assessment form. Seven levels of cognitive functioning can be determined, ranging from a score of 0 (intact) to 6 (severely cognitively impaired). The scores are obtained from five MDS items, ie, one communication item (ability to make self understood), three cognitive items (short-term memory if comatose and decision-making), and one item for activities of daily living (eating). The CPS measure correlates highly $(r \geq 0.70)$ with the frequently used Folstein Mini-Mental Status Examination (MMSE) ${ }^{70}$ a tool used systematically to assess mental status. ${ }^{71}$ Validation testing of CPS scoring against the MMSE shows a sensitivity of 0.94 and a specificity 


\section{Total subject assessments}

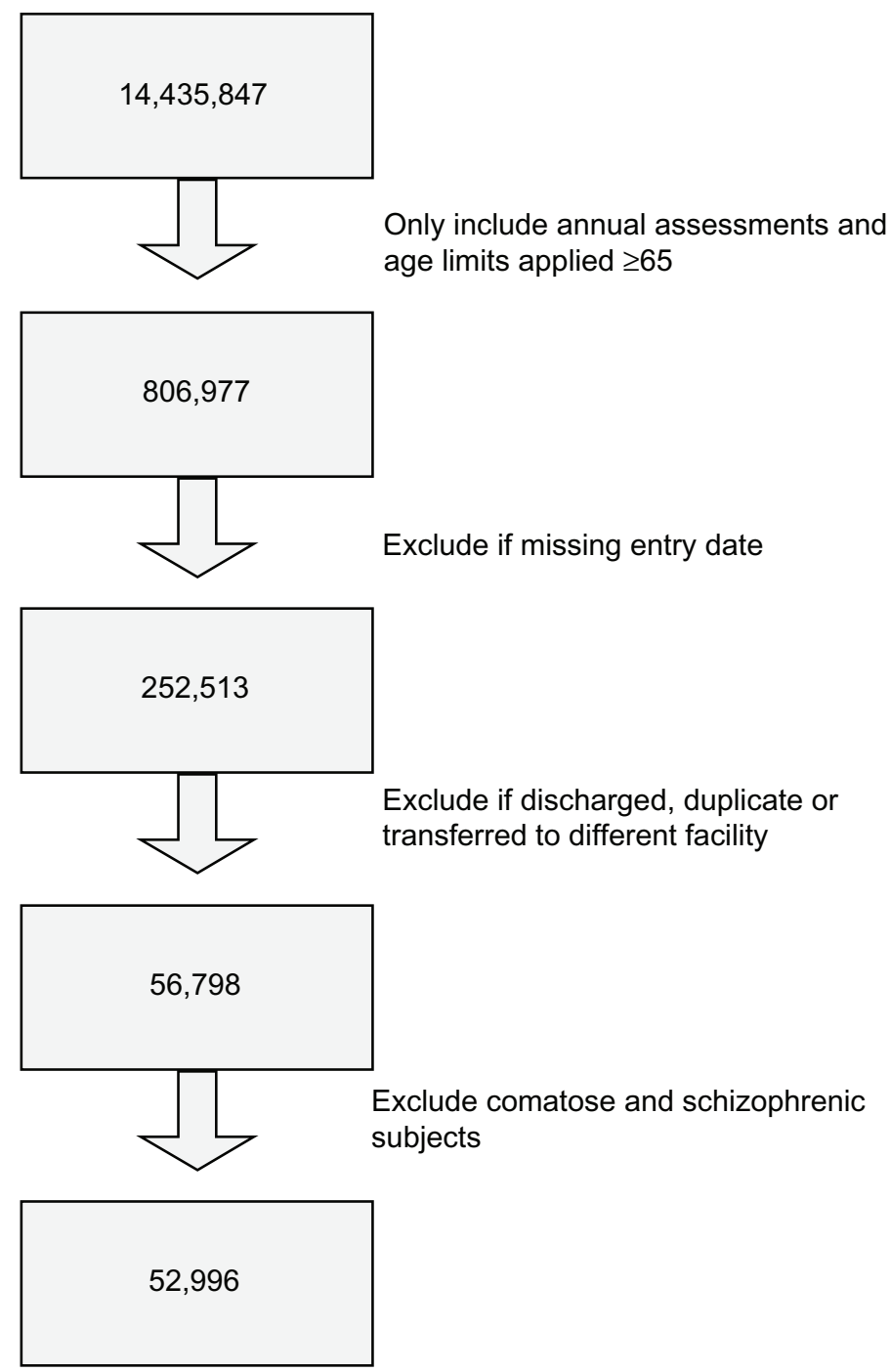

Figure I Sample method.

of 0.94. MMSE scores range from 0 to 30 . A score of $0-9$ denotes severe impairment, 10-18 is moderate, 19-24 is mild, and scores $>24$ indicate that the individual's cognitive status is intact. The MMSE scores are converted into CPS scores. A CPS score of 5-6 correlates with severe impairment, 3-4 with moderate impairment, 2 with mild impairment, and 0-1 with borderline intact to intact. The CPS scores are converted into average MMSE values, ie, 3 is a mean MMSE of 15.4 (moderate impairment) and a CPS score of 4-5 is a mean MMSE of 5-6 (severe cognitive impairment). ${ }^{72}$

The Pain Scale devised by Fries et al uses two items from the MDS instrument, ie, item J2a for pain frequency and item $\mathrm{J} 2 \mathrm{~b}$ for pain intensity. If pain frequency is marked as "no pain", subsequent pain intensity and pain sites are not scored.
The Pain Scale devised by Fries et a ${ }^{73}$ was validated against a standardized pain instrument, ie, the Visual Analog Scale, and has shown validity in detecting pain in intact to moderately cognitively impaired residents. The Pain Scale was not performed in a validation sample for severely cognitively impaired residents, because these residents were unable to perform the Visual Analog Scale. The limitation of using this tool in significantly cognitively impaired residents was also indicated in the instrument validation study of Fries et al, indicating that the percentage of residents reporting no pain increased with increasing cognitive impairment. ${ }^{73}$ The potential to use the Pain Scale in addition to other indicators was the impetus for testing a theoretical construct to improve pain detection in residents with severe cognitive impairment, 
because pain frequency and intensity alone might not fully capture the pain spectrum in those with limited capacity to verbalize pain.

\section{Data collection}

Data from 2001, 2002, and 2003 were collected from annual assessment of deidentified residents in Medicare-certified nursing homes from across the United States (http://www. resdac.umn.edu/MDS/data_available.asp). At the time of analysis, 2001-2003 were the latest data sets available and ready for analysis. A proposed model panel was evaluated for model fit by a series of steps using MDS-RAI data. The goal was to identify the dimensions (indicators) of the measurement instrument, clarify the order of the measurement levels, and examine the integrity of the measurement instruments. The study was conducted to compare statistical models of pain, while grouping residents by cognitive status. The model contains affective, behavioral, and inferred pain traits grouped by cognitive status (see Figure 2). The model was compared for utility with the existing pain instrument devised by Fries et al. The Pain Scale is widely used as a secondarily derived tool using MDS data.

\section{Statistical analysis}

Descriptive statistics and factor analyses were run with SPSS 14.0 (SPSS Inc, Chicago, IL). Advanced multivariate techniques were used to build a measurement model and to test the model fit with structural equation modeling. A measurement model of pain was hypothesized based on current research and literature of the domains and dimensions of pain in the elderly. Ordinal level correlations were run with Spearman's rho. A latent model of pain was built with AMOS 6.0 to determine how well 12 indicators from the MDS-RAI represented the latent construct of pain. Equality constraints were applied to compare four cognitive levels of residents, ie, intact, mild, moderate, and severe cognitive impairment. Construct validity was evaluated by the extent to which the

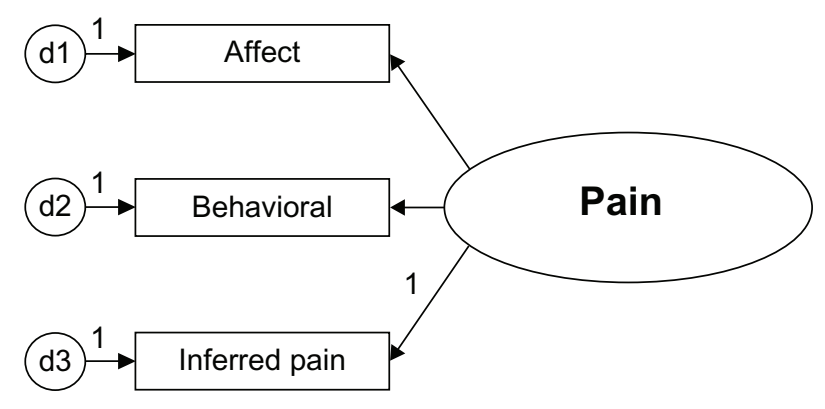

Figure 2 Latent construct pain. measurement of pain accurately represents the construct and assumes a theoretical basis.

A critical step in building the model was hypothesizing associations based on conceptual relationships, not simply based on the data available. Content validity or logical validity was evaluated in the model to determine if indicators represent all dimensions of the construct of pain. The Pain Scale devised by Fries et $\mathrm{al}^{73}$ contains only two indicators, ie, pain frequency $(\mathrm{J} 2 \mathrm{a})$ and pain intensity $(\mathrm{J} 2 \mathrm{~b})$ in an ordinal scale. These two indicators yield an underidentified model and cannot run as a stand-alone model in AMOS. These items were highly correlated ( $\mathrm{r}=0.977, P=0.01$, one-tailed), indicating that one of these items could be dropped, because they closely measure the same aspect of the inferred pain dimension. These core indicators of pain are included in the hypothesized model for testing to define the dimension of inferred pain.

Confirmatory analysis was undertaken to review factor loadings. Confirmatory factor analysis was used to reduce the factors and confirm factor groupings, ie, inferred pain, affect, and behaviors. The measurement model was evaluated for validity and goodness of fit statistics to improve the model to ensure the final prototype is parsimonious. Indicators with a probability of 0.01 were included, and non-significant items were not included in the model. The specification of free and fixed elements represents the initial hypothesis that presumes indirect or direct effects among latent variables. ${ }^{74}$ The assessment of power in structural equation modeling is complex, because there are substantially more parameters beyond a straightforward procedure like the $t$-test and analysis of variance, which contain only a few parameters. ${ }^{74}$ The sample size was considerable $(n=52,996)$, so power analysis was not critical to determining an appropriate sample size prior to the study to ensure statistical significance of the findings.

\section{Results}

The selected MDS items were collected for 52,996 residents. Overall, $80 \%$ of the sample was female and the average age was 84 years (see Table 2). Of the medical conditions selected, arthritis was the most prevalent (34.2\%), with diabetes affecting around 20.9\% (see Table 3 ). The most common pain site was the joints $(14.9 \%)$.

Table 4 contains an index of behaviors, which with additional models could clarify the antecedents and consequences of pain. The Pain Scale items (see Table 5) indicated that $68.8 \%$ reported no pain, while only $12.8 \%$ experienced pain daily. Pain frequency and intensity declined as cognitive status declined, indicating that only $18.2 \%$ of residents 
Table 2 Demographic table of resident characteristics

\begin{tabular}{|c|c|c|}
\hline$(n=52,996)$ & $\begin{array}{l}\text { Mean } \pm \text { SD } \\
\mathbf{N} \text { (percent) }\end{array}$ & Range \\
\hline Age & $83.7 \pm 8.1$ & $65-112$ \\
\hline \multicolumn{3}{|l|}{ Gender } \\
\hline Male & 10,798 (20.4\%) & \\
\hline Female & 42,198 (79.6\%) & \\
\hline \multicolumn{3}{|l|}{ Cognitive status } \\
\hline Mean CPS score & $2.9 \pm 1.9$ & $0-6$ \\
\hline Mean MMSE & $14.4 \pm 8.0$ & $0.4-24.5$ \\
\hline Intact & $7,428(14.0 \%)$ & \\
\hline Mild & $13,928(26.3 \%)$ & \\
\hline Moderate & $15,216(28.7 \%)$ & \\
\hline Severe & $16,424(31.0 \%)$ & \\
\hline \multicolumn{3}{|l|}{ Marital status } \\
\hline Never married & $12.7 \%$ & \\
\hline Married & $15.5 \%$ & \\
\hline Widowed & $62.3 \%$ & \\
\hline Separated & $2.2 \%$ & \\
\hline Divorced & $7.3 \%$ & \\
\hline \multicolumn{3}{|l|}{ Ethnicity } \\
\hline American Indian/Alaskan natives & $0.3 \%$ & \\
\hline Asian/Pacific islander & $1.2 \%$ & \\
\hline Black, not of Hispanic origin & $11.4 \%$ & \\
\hline Hispanic & $2.9 \%$ & \\
\hline White, not of Hispanic origin & $84.2 \%$ & \\
\hline \multicolumn{3}{|l|}{ Language } \\
\hline English & $94.6 \%$ & \\
\hline Spanish & $2.4 \%$ & \\
\hline French & $0.2 \%$ & \\
\hline Other & $2.8 \%$ & \\
\hline \multicolumn{3}{|l|}{ Education level } \\
\hline No schooling & $3.0 \%$ & \\
\hline 8 th grade/less & $30.8 \%$ & \\
\hline 9-1I grade & $14.2 \%$ & \\
\hline High school & $33.2 \%$ & \\
\hline Technical or trade school & $4.2 \%$ & \\
\hline Some college & $7.2 \%$ & \\
\hline Bachelor's degree & $4.2 \%$ & \\
\hline Graduate degree & $1.8 \%$ & \\
\hline Not coded/missing & $1.5 \%$ & \\
\hline
\end{tabular}

Abbreviations: CPS, Cognitive performance scale; MMPE, Folstein mini mental status examination.

with cognitive severe impairment were experiencing pain, while $47.7 \%$ of the intact group experienced pain daily or less than daily. This suggests that underdetection of pain was more likely as cognition declined, assuming the same relative comorbidities between cognitively intact and impaired residents.

Initial and final models were built from the original pain model using the dimensions of affective, behavioral, and inferred pain grouped by cognitive status. Careful consideration was given to what items to include in the initial model (see Figure 3, Tables 6 and 7) based on current empirical findings of reported pain symptoms and behaviors. All of
Table 3 Diseases/events with potential pain symptoms

\begin{tabular}{llc}
\hline Diseases & $\begin{array}{l}\text { Number from total } \\
(\mathbf{n}=\mathbf{5 2}, \mathbf{9 9 6})\end{array}$ & $\begin{array}{r}\text { Percent } \\
\text { of total }\end{array}$ \\
\hline Diabetes & 11,063 & $20.9 \%$ \\
Peripheral vascular disease & 6,128 & $11.6 \%$ \\
*Arthritis & 18,110 & $34.2 \%$ \\
Complaint of joint pain & 7,703 & $14.5 \%$ \\
*Hip fracture & 2,113 & $4.0 \%$ \\
Multiple sclerosis & 440 & $0.8 \%$ \\
Emphysema/COPD & 6,423 & $12.1 \%$ \\
*Cancer & 2,844 & $5.4 \%$ \\
Renal failure & 1,327 & $2.5 \%$ \\
*Pneumonia & 472 & $0.9 \%$ \\
Respiratory infection & 1,213 & $2.3 \%$ \\
Septicemia & 28 & $0.1 \%$ \\
*Urinary tract & 2,737 & $5.2 \%$ \\
infection (UTI) & & \\
Wound infection & 285 & $0.5 \%$ \\
\hline
\end{tabular}

Note: *Key diagnoses used for pain diagnosis scoring.

the indicators in the measurement model were statistically significant $(P<0.01$, see Table 8$)$. Correlations are used to test for association but not for causality. The inferences made should have a logical connection with each other. It is important to examine both the degree of the relationship and the $P$ value. Research has a tendency to disregard weak correlations, but a linear relationship may have meaning in terms of current knowledge when examined in the context of other variables.

Cumulative scores of five potential pain-causing diseases (arthritis, hip fracture, cancer, pneumonia, and urinary tract infection) were evaluated as an indicator for pain. While cumulative pain diagnoses were significant at the $P<0.01$ level, the correlation was low $(\mathrm{r}=0.182)$. In efforts to build a parsimonious model, the indicators of pain frequency, intensity, and cumulative pain site scores were retained, and potential pain diagnosis scoring were not included in the preliminary model.

Both models were recursive. The modification indices were examined for correlating measurement errors to reduce the chisquare and degrees of freedom from $\chi^{2}=305889.3, \mathrm{df}=249$, $P<0.01$ in the original model to $\chi^{2}=4933.4$, $\mathrm{df}=143$, $P<0.01$ in the corrected model (Figure 4, Table 9).

The differences between the chi-square $\left(\Delta \chi^{2}\right)$ and the degrees of freedom (df) of the two models were compared to assess the model improvement from the initial model with 12 indicators to the final model with ten indicators:

$$
\begin{aligned}
\Delta \chi^{2} & =\frac{\chi_{0}^{2}-\chi_{1}^{2}}{\mathrm{df}_{0}-\mathrm{df}_{1}} 30589.3-4933.4 / 249-143=25655.9 / 106 \\
& =242.04
\end{aligned}
$$


Table 4 Behavioral index

\begin{tabular}{|c|c|c|c|c|}
\hline Cognitive status & $\begin{array}{l}\text { Intact } \\
(n=7,428)\end{array}$ & $\begin{array}{l}\text { Mild } \\
(n=\mid 3,928)\end{array}$ & $\begin{array}{l}\text { Moderate } \\
(n=|5,2| 6)\end{array}$ & $\begin{array}{l}\text { Severe } \\
(n=16,424)\end{array}$ \\
\hline \multirow[t]{2}{*}{ Change in behavioral symptoms } & I0I Improved (I.4\%) & $348(2.5 \%)$ & 645 (4.2\%) & $821(5.0 \%)$ \\
\hline & I I0 Deteriorated (I.5\%) & $357(2.6 \%)$ & $792(5.2 \%)$ & 792 (4.8\%) \\
\hline \multicolumn{5}{|l|}{ Pain behavior } \\
\hline \multicolumn{5}{|l|}{ Affect/nonverbal cues } \\
\hline (EID) Persistent anger & $751(10.1 \%)$ & $1,840(13.2 \%)$ & $2,839(18.6 \%)$ & $2,033(12.4 \%)$ \\
\hline (EIK) Insomsnia & 197 (2.6\%) & $378(2.7 \%)$ & 595 (3.9\%) & $560(3.4 \%)$ \\
\hline (EIL) Sad facial expressions & $173(10 \%)$ & $2,197(15.8 \%)$ & $3,558(23.4 \%)$ & $3,647(22.2 \%)$ \\
\hline (EIM) Crying & $245(3.3 \%)$ & $715(5.2 \%)$ & $\mathrm{I}, \mathrm{I} 58(7.6 \%)$ & $\mathrm{I}, 452(8.9 \%)$ \\
\hline (EIO) Withdrawal & 107 (I.4\%) & $394(2.8 \%)$ & $574(3.8 \%)$ & $659(4.1 \%)$ \\
\hline (EIP) Reduced social interaction & $196(2.6 \%)$ & $546(3.9 \%)$ & 744 (4.9\%) & $813(4.9 \%)$ \\
\hline (E2) Persistence & I,742 (23.4\%) & $4,514(32.4 \%)$ & $6,895(45.3 \%)$ & $6,726(40.9 \%)$ \\
\hline \multicolumn{5}{|l|}{ Verbal cues } \\
\hline (EIA) Negative statements & $|8|(2.4 \%)$ & 489 (3.6\%) & 711 (4.6\%) & 307 (1.9\%) \\
\hline (EIB) Repetitive questions & $34(0.4 \%)$ & $426(3.1 \%)$ & I,949 (I $2.8 \%)$ & $\mathrm{I}, 085(6.6 \%)$ \\
\hline (EIC) Repetitive verbalizations & $68(0.9 \%)$ & $355(2.5 \%)$ & $\mathrm{I}, 306(8.6 \%)$ & $\mathrm{I}, 63 \mathrm{I}(9.9 \%)$ \\
\hline (EIE) Self deprecation & $79(1.1 \%)$ & $277(2.0 \%)$ & $312(2.1 \%)$ & $115(.7 \%)$ \\
\hline$(E I H)$ Health complaints & $776(10.5 \%)$ & I,572 (II.3\%) & $1,386(9.1 \%)$ & $380(2.3 \%)$ \\
\hline (EII) Anxious complaints & $693(9.3 \%)$ & $\mathrm{I}, 853(\mathrm{I} 3.3 \%)$ & $2,524(16.6 \%)$ & $960(5.9 \%)$ \\
\hline (E4BA) Verbally abusive frequency & $304(4.1 \%)$ & $943(6.7 \%)$ & $2,194(14.4 \%)$ & I,915 (11.7\%) \\
\hline \multicolumn{5}{|l|}{ Physical cues } \\
\hline $\begin{array}{l}\text { (E4DA) Inappropriate behavior frequency; disruptive sounds, } \\
\text { noisiness, screaming, self-abuse acts, sexual behavior } \\
\text { or disrobing in public, smeared/threw feces, hoarding, } \\
\text { rummaging through other's belongings }\end{array}$ & $178(2.5 \%)$ & 857 (6.2\%) & $2,273(14.9 \%)$ & $3,344(20.4 \%)$ \\
\hline (E4DB) Inappropriate behavior alterability & $108(1.5 \%)$ & $505(3.6 \%)$ & $1,420(9.3 \%)$ & $2,326(14.2 \%)$ \\
\hline (B5D) Restlessness & $65(0.9 \%)$ & $689(4.9 \%)$ & $3,023(19.8 \%)$ & $5,772(35.1 \%)$ \\
\hline (EIN) Repetitive physical movements; pacing, & $100(1.4 \%)$ & 621 (4.4\%) & $2,158(14.2 \%)$ & $3.855(23.5 \%)$ \\
\hline \multicolumn{5}{|l|}{ hand wringing, restlessness, fidgeting, picking } \\
\hline (E4AA) Wandering frequency & $5(0.1 \%)$ & $187(\mathrm{I} .4 \%)$ & $\mathrm{I}, 874(\mathrm{I} 2.3 \%)$ & $2,755(16.8 \%)$ \\
\hline (E4AB) Wandering alterability & 2 & $68(0.5 \%)$ & 900 (5.9\%) & $1,699(10.3 \%)$ \\
\hline (E4CA) Physically abusive frequency & $37(0.5 \%)$ & $223(1.7 \%)$ & I,068 (7.1\%) & $2,094(12.7 \%)$ \\
\hline (E4CB) Physically abusive alterability & $23(0.3 \%)$ & $97(0.7)$ & $617(4.1 \%)$ & $\mathrm{I}, 368(8.3 \%)$ \\
\hline (E4EA) Resists care frequency & $387(5.1 \%)$ & $\mathrm{I}, 4 \mathrm{I} 7(\mathrm{I} 0.3 \%)$ & $3,375(22.2 \%)$ & $4,934(30.0 \%)$ \\
\hline (E4EB) Resists care alterability & 287 (3.9\%) & $972(7.0 \%)$ & $2,244(\mid 4.7 \%)$ & $3,392(20.7 \%)$ \\
\hline
\end{tabular}

Comparing the original model with the final model shows a large gap, and therefore increases the probability that the changed model is improved. The behavioral item "physically abusive" (E4CA) was dropped due to weak correlations and a non-significant factor loading $(P=0.288)$. The inferred pain component, unsteady gait (J1N), was also dropped due to weak correlations and to improve the model parsimony for the inferred dimension of pain. The final revised model allows measurement errors to be correlated with each other and better capture shared measurement errors for more correlated items. Chi-square values of the model were expected to be large, because of the sample size. Model fit statistics are found in Table 10 (see Table 11 for definitions of goodness of fit statistics).

The model fit was greatly improved from the initial to the final model. Reduced root mean square residuals were achieved and the goodness of fit further approached 1.0 with the adjustments made. The Tucker-Lewis index values should be between 0 and 1 , and the adjusted model indicates a value of 0.965 . Values close to 1.0 indicate a very good fit. Scores for root mean square error of approximation are ideally below 0.05 , and the changes made reduced this value to 0.025 .

In comparison, the model fit by cognitive status with a side-by-side evaluation (Figure 4), notable variations in correlations occur within inferred pain domains, especially comparing intact/mild with moderate/severe cognitive states. The intact/mild groups and the moderate/severe groups showed similar values for associations and correlated errors for inferred pain items (ie, J2a pain frequency, J2b pain intensity, and cumulative score of pain sites). This information is helpful in understanding the relationship between resident cognition and how further dimensions (eg, behavioral, 
Table 5 Fries pain scale (PS) ratings

\begin{tabular}{|c|c|c|c|c|c|}
\hline Fries pain indicators & $\begin{array}{l}\text { Total population } \\
(n=52,996)\end{array}$ & $\begin{array}{l}\text { Intact } \\
(n=7,428)\end{array}$ & $\begin{array}{l}\text { Mild } \\
(n=13,928)\end{array}$ & $\begin{array}{l}\text { Moderate } \\
(n=15,2 \mid 6)\end{array}$ & $\begin{array}{l}\text { Severe } \\
(n=16,424)\end{array}$ \\
\hline \multicolumn{6}{|l|}{ Pain frequency (J2a) } \\
\hline No pain & $36,470(68.8 \%)$ & $3,887(52.3 \%)$ & $8,4 I I(60.4 \%)$ & 10,737 (70.6\%) & |3,435 (8I.8\%) \\
\hline Pain less than daily & 9,731 (I8.4\%) & I,869 (25.2\%) & $3,144(22.6 \%)$ & $2,796(18.4 \%)$ & I,922 (I I.7\%) \\
\hline Pain daily & 6,795 (I2.8\%) & I,672 (22.5\%) & $2,373(17.0 \%)$ & I,683 (II.0\%) & $\mathrm{I}, 067(6.5 \%)$ \\
\hline Pain totals & $16,526(31.2 \%)$ & $3,54 \mid(47.7 \%)$ & 5,5 I 7 (39.6\%) & $4,479(29.4 \%)$ & $2,989(18.2 \%)$ \\
\hline \multicolumn{6}{|l|}{ Pain intensity $(\mathrm{J} 2 \mathrm{~b})$} \\
\hline Mild pain & $\begin{array}{l}8,046 \text { ( } 15.2 \% \text { of total, or } \\
49 \% \text { within reported pain) }\end{array}$ & I,5I $4(20.4 \% / 42.8 \%)$ & 2,608 (I8.7\%/47.3\%) & 2,295 (I5.I\%/ 5I.2\%) & I,629 (9.9\%/54.5\%) \\
\hline Moderate pain & 7,946 (I5\%/48\%) & I,873 (25.2\%/52.9\%) & $2,73 \mid(19.6 \% / 49.5 \%)$ & 2,065 (I3.6\%/ 46. I\%) & I,277 (7.8\%/42.7\%) \\
\hline Horrible/excruciating & $534(1 \% / 3 \%)$ & $154(2.1 \% / 4.3 \%)$ & $178(1.3 \% / 3.2 \%)$ & $119(.8 \% / 2.7 \%)$ & $83(0.5 \% / 2.8 \%)$ \\
\hline Total & 16,526 & $3,54 I$ & 5,517 & 4,479 & 2,989 \\
\hline
\end{tabular}

affective, and cognitive) add further detail to clarifying the pain construct. The overall model fit indicates utility across all cognitive levels (Figure 5). Pain scores could be converted to a standardized score, including all of the indicators to a converted $t$-score, the factorial scores could be retained using a weighted score, or pain indicators could simply be added for a cumulative score.

\section{Discussion}

The findings of this study support the pragmatic utility of additional measures to detect pain in the elderly beyond selfreports of pain intensity and frequency. Research working towards further defining dimensions of pain in the elderly increases our ability to understand and assess pain characteristics in this population. Findings of primary concern

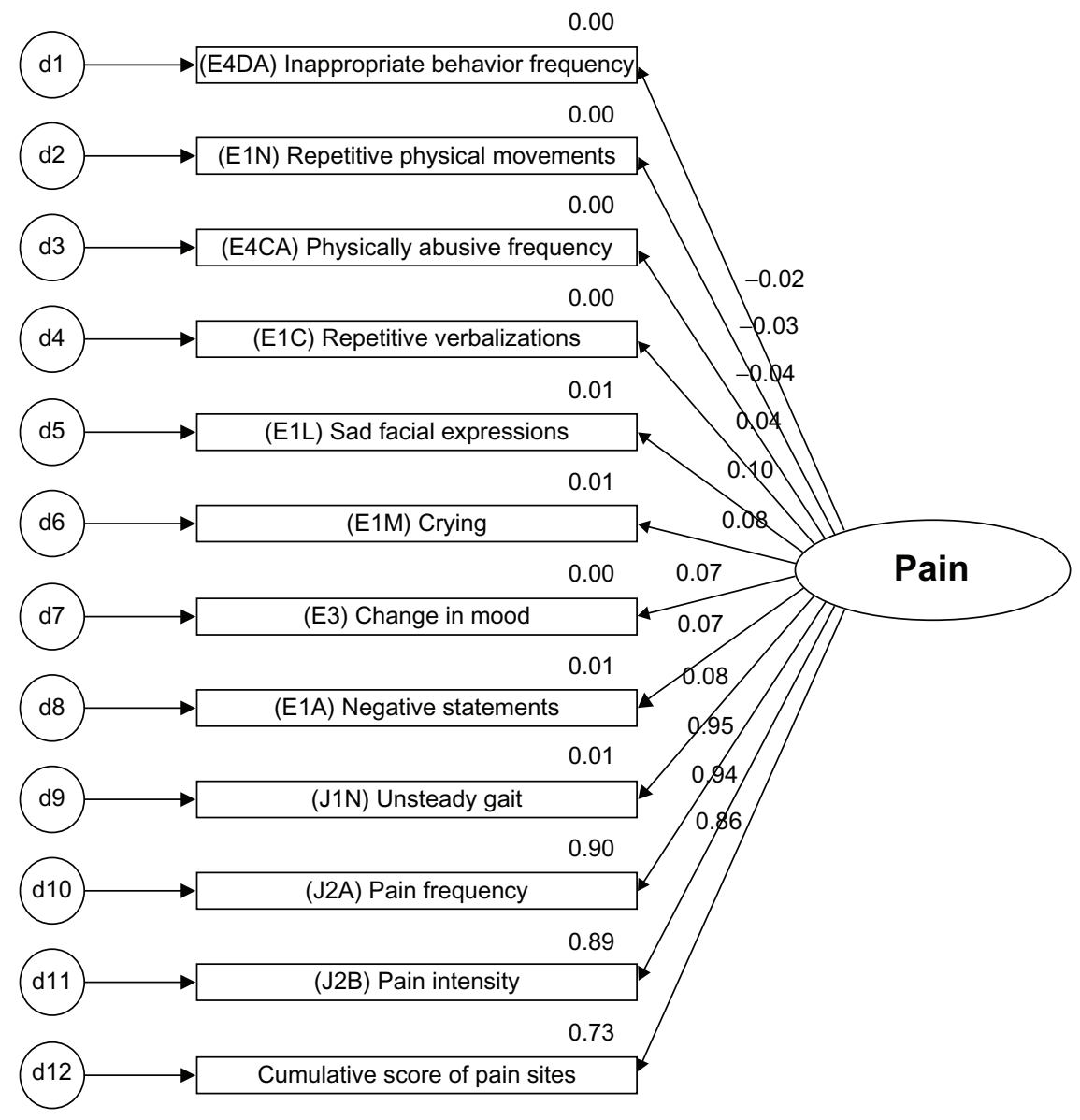

Figure 3 Preliminary indicators in model. 
Table 6 Preliminary model factoring loadings

\begin{tabular}{llllll}
\hline & Est & SE & CR & $P$ & Label \\
\hline Pain & & & & & \\
(Cum) Pain score 200I & 1.000 & & & & \\
(J2B) Pain intensity & 1.034 & 0.003 & 311.057 & $* * *$ & $\mathrm{k}$ \\
(J2A) Pain frequency & 0.943 & 0.003 & $313.01 \mathrm{I}$ & $* * *$ & $\mathrm{j}$ \\
(JIN) Unsteady gait & 0.046 & 0.003 & $15.93 \mathrm{I}$ & $* * *$ & $\mathrm{i}$ \\
(EIA) Neg state & 0.019 & $0.00 \mathrm{I}$ & 15.045 & $* * *$ & $\mathrm{~h}$ \\
(E3) Mood change & 0.046 & 0.003 & $16.5 \mathrm{II}$ & $* * *$ & $\mathrm{~g}$ \\
(EIM) Crying & 0.035 & 0.002 & 21.770 & $* * *$ & $\mathrm{f}$ \\
(EIL) Worried face & 0.085 & 0.003 & 27.922 & $* * *$ & $\mathrm{e}$ \\
(EIC) Repeat verb & 0.016 & $0.00 \mathrm{I}$ & $\mathrm{II} .887$ & $* * *$ & $\mathrm{~d}$ \\
(E4CA) Phys abusive & $-0.00 \mathrm{I}$ & $0.00 \mathrm{I}$ & -1.062 & 0.288 & $\mathrm{c}$ \\
(EIN) Repeat moves & 0.009 & 0.002 & 5.090 & $* * *$ & $\mathrm{~b}$ \\
(E4DA) Dis behavior & 0.008 & 0.003 & 2.794 & 0.005 & $\mathrm{a}$ \\
\hline
\end{tabular}

Note: ***Significantly different from zero at the 0.001 level (two-tailed). Abbreviations: SE, standard error; CR, critical ratio.

substantiate research to date ${ }^{75}$ on pain in those residents with severe cognitive impairment, along with the contribution of behavioral indicators to identification of pain beyond selfreport measures.

The Pain Scale items (Table 5) indicated that the majority of the sample (68.8\%) were not experiencing pain. When this total was broken down by cognitive status, as the cognitive state declined, pain frequency and intensity also appeared to decline. Forty-eight percent of the cognitively intact group was reported as experiencing pain, while only $18.2 \%$ of those with severe cognitive impairment were assessed as having pain. These findings support other research to date indicating that pain is potentially under-reported in this population. ${ }^{4,22,75-79}$

Prior models of pain have included cognitive, affective, and behavioral components. ${ }^{20,33,80-82}$ The latent construct of pain could include these three dimensions as a discrete measure in a model. Because this study was used as a stacked comparison, cognitive items were used as the grouping variable and not as a separate measure in the pain model. The goal was to gain an understanding of the overall fit of the model by cognitive state. Future studies could examine this construct using cognition, affect, and behavior as separate measures.

Self-reported measures of pain could be further validated by more objective assessment. From a theoretical perspective, evaluation of the proposed models and indicators is not exhaustive of all the potential cues within the dimensions of cognition, affect, behavioral, and inferred pain indicators that could explain the construct of pain. The research was limited to the available items from the MDS. Important in the use of

Table 7 Definitions of the indicators

\begin{tabular}{|c|c|}
\hline \multicolumn{2}{|l|}{ Indicators } \\
\hline Variable & Description \\
\hline \multicolumn{2}{|l|}{ Inferred/reported pain } \\
\hline (J2A) Pain frequency & Frequency resident complains or shows evidence of pain \\
\hline (J2B) Pain intensity & Intensity of pain described or displayed by the resident \\
\hline Pain sites score & Cumulative pain site index, items J2a-J3j, KIc; higher scores indicates more pain sites \\
\hline$(J I N)$ Unsteady gait & $\begin{array}{l}\text { Problem present in last } 7 \text { days; Resident appears unbalanced, uncoordinated, jerking movements, } \\
\text { careless movements, slow gait, shuffling steps or wide-based gait with halting steps }\end{array}$ \\
\hline \multicolumn{2}{|l|}{ Affect } \\
\hline (EIL) Sad facial expressions & Sad, pained, worried facial expressions, ie furrowed brows \\
\hline (EIM) Crying & $\begin{array}{l}\text { Indicator of distress. Behavior is recorded by frequency in the last } 30 \text { days irrespective of the } \\
\text { cause of the behavior (indicator) }\end{array}$ \\
\hline (E3) Change in mood & $\begin{array}{l}\text { Refers to status of any symptoms described in section E (mood); snapshot of current observation } \\
\text { period, not just a point in time }\end{array}$ \\
\hline (EIA) Negative statements & $\begin{array}{l}\text { Resident made negative statements, eg, "Nothing matters, would rather be dead, what's the use, } \\
\text { regrets having lived so long" }\end{array}$ \\
\hline \multicolumn{2}{|l|}{ Behavioral } \\
\hline (EIC) Repetitive verbalizations & Calling out for help, repeated statements \\
\hline (E4DA) Inappropriate behavior frequency & $\begin{array}{l}\text { Disruptive sounds, noisiness, screaming, self-abuse acts, sexual behavior or disrobing in public, } \\
\text { smeared/threw feces, hoarding, rummaging through other's belongings }\end{array}$ \\
\hline (EIN) Repetitive physical movements & Pacing, hand wringing, restlessness, fidgeting, picking \\
\hline (E4CA) Physically abusive frequency & Others are hit, shoved, scratched, sexually abused \\
\hline \multirow[t]{5}{*}{ Cognition } & Grouping variable of the comparative models; cognitive performance algorithm scale \\
\hline & $0=\ln$ tact \\
\hline & $\mathrm{I}=$ Mild \\
\hline & $2=$ Moderate \\
\hline & $3=$ Severe \\
\hline
\end{tabular}


Table 8 Correlation matrix of the indicators of pain

\begin{tabular}{|c|c|c|c|c|c|c|c|c|c|c|c|c|}
\hline Indicators & $\mathbf{I}$ & 2 & 3 & 4 & 5 & 6 & 7 & 8 & 9 & 10 & II & 12 \\
\hline I. Sad facial expressions & 1.000 & & & & & & & & & & & \\
\hline 2. Crying & 0.339 & 1.0 & & & & & & & & & & \\
\hline 3. Change in mood & 0.167 & 0.131 & 1.0 & & & & & & & & & \\
\hline 4. Negative statements & 0.199 & 0.150 & 0.115 & 1.0 & & & & & & & & \\
\hline 5. Repetitive verbalizations & 0.213 & 0.154 & 0.086 & 0.153 & 1.0 & & & & & & & \\
\hline 6. Inappropriate behavior & 0.151 & 0.114 & 0.064 & 0.086 & 0.316 & 1.0 & & & & & & \\
\hline 7. Repetitive physical movements & 0.254 & 0.145 & 0.092 & 0.059 & 0.239 & 0.292 & 1.0 & & & & & \\
\hline 8. Physically abusive & 0.109 & 0.074 & 0.045 & 0.062 & 0.124 & $0.28 I$ & 0.188 & 1.0 & & & & \\
\hline 9. Unsteady gait & 0.054 & 0.024 & 0.036 & 0.031 & 0.014 & 0.021 & 0.057 & 0.031 & 1.0 & & & \\
\hline 10. Pain frequency & 0.090 & 0.073 & 0.060 & 0.067 & 0.032 & -0.025 & -0.027 & -0.042 & 0.075 & 1.0 & & \\
\hline II. Pain intensity & 0.095 & 0.079 & 0.063 & 0.068 & 0.035 & -0.026 & -0.026 & -0.042 & 0.073 & 0.977 & 1.0 & \\
\hline 12. Cumulative pain site score & 0.095 & 0.078 & 0.061 & 0.072 & 0.035 & -0.024 & -0.025 & -0.042 & 0.082 & 0.965 & 0.964 & 1.0 \\
\hline
\end{tabular}

Note: All correlation coefficients are significant at the 0.01 level (one-tailed).

large data sets is having a clear clinical and evidential base to substantiate why certain indicators are used and not others. ${ }^{83}$ Hypothesized indicators chosen from the MDS were based on knowledge and research conducted to this point. Theoretical modeling can start a dialog concerning other indicators which are potentially useful and shown from previous smaller-scale studies to indicate pain beyond self-reports from the resident, such as the use of nonverbal pain scales. Correlations between indicators can clarify the degree of association between the dimensions and unique relationships between behaviors. As our understanding of pain increases, clinicians will be better equipped to measure quality initiatives in the assessment, treatment, and prevention of pain.

Focusing interventions only on severely cognitively impaired residents, ie, those at high risk for untreated pain, fails to take into account factors at the population level, and would limit options to reduce the burden of chronic pain for all residents in longterm care. ${ }^{84} \mathrm{~A}$ need exists for continued quality improvement

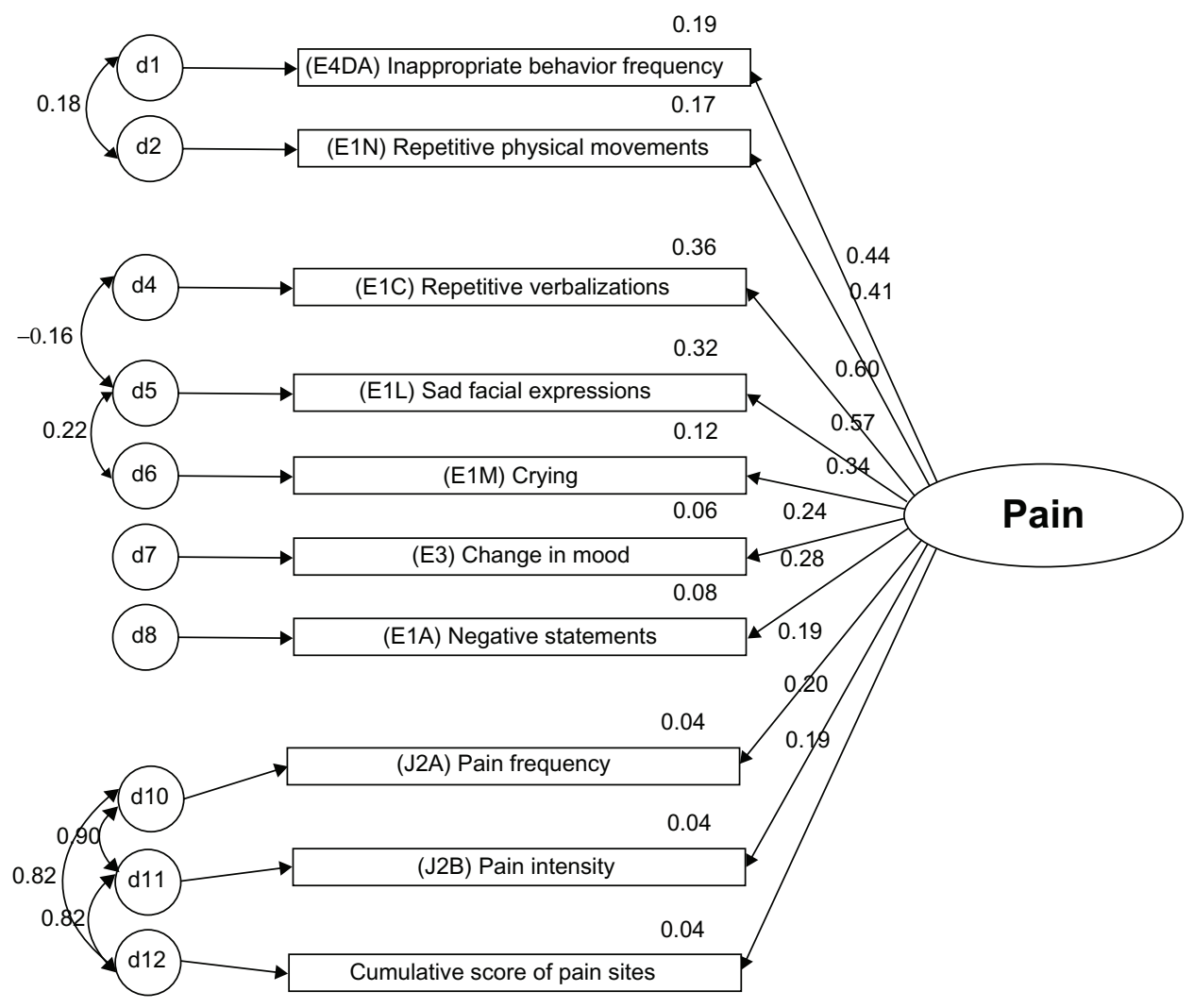

Figure 4 Final model. 
Intact

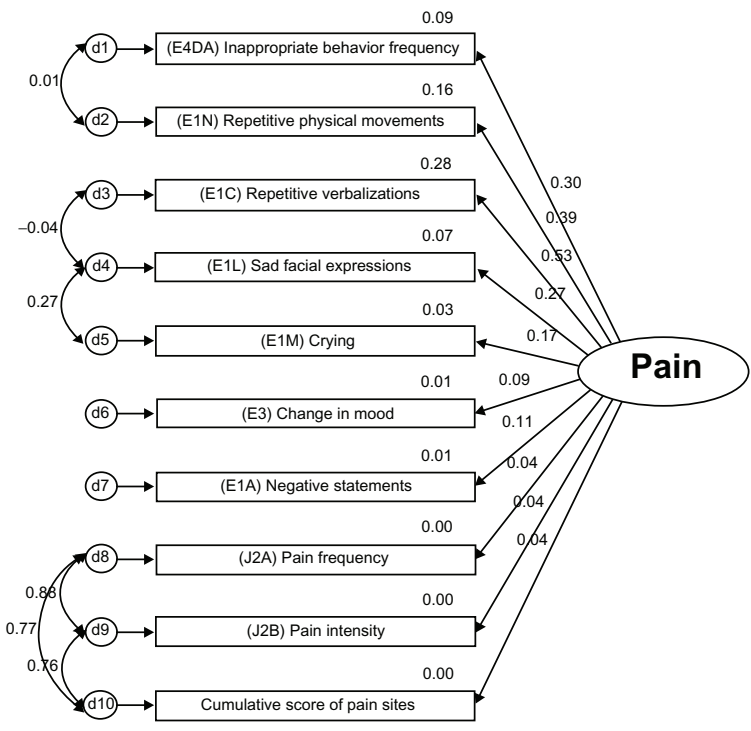

Moderate

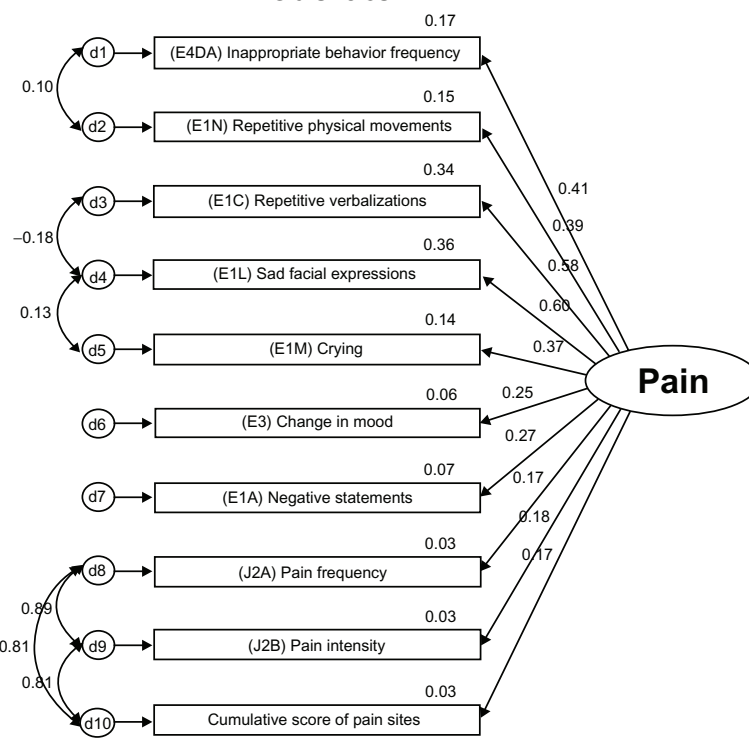

Mild

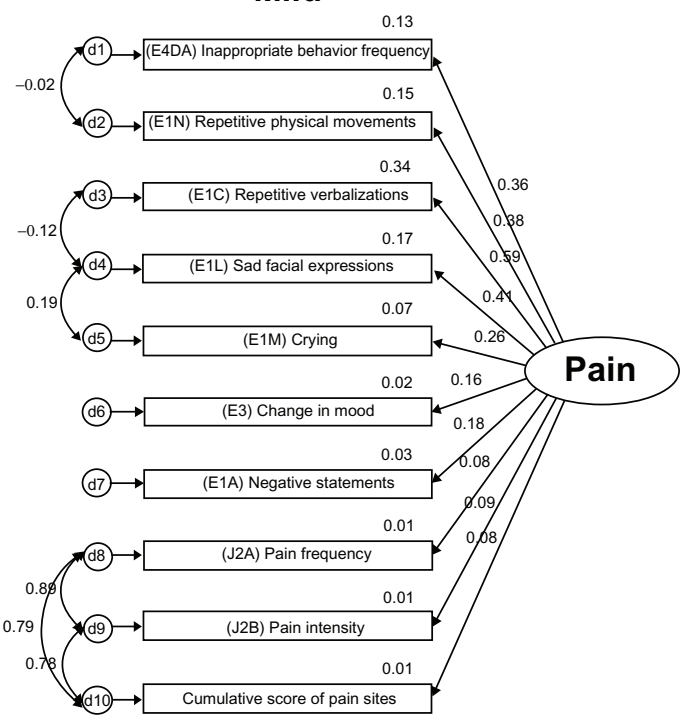

Severe

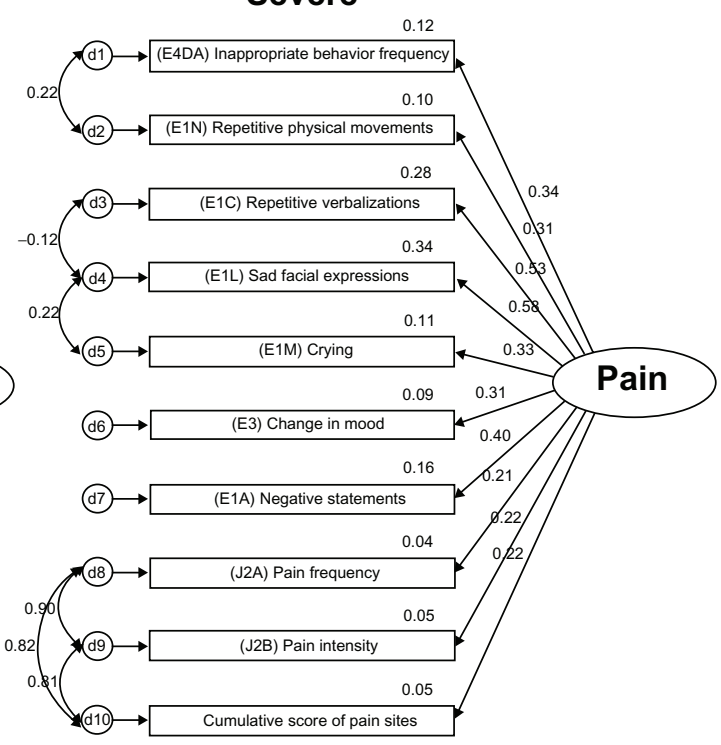

Figure 5 Measurement models by cognitive status with correlations and shared error.

Table 9 Final model factor loadings

\begin{tabular}{llllll}
\hline & Est & SE & CR & P & Label \\
\hline Pain & & & & & \\
(Cum) pain site 200I & 1.000 & & & & \\
(J2B) Pain intensity & 1.024 & 0.030 & 34.198 & $* * *$ & $\mathrm{i}$ \\
(J2A) Pain frequency & 0.879 & 0.026 & 33.856 & $* * *$ & $\mathrm{~h}$ \\
(EIA) Neg state & 0.373 & 0.022 & 16.645 & $* * *$ & $\mathrm{~g}$ \\
(E3) Mood change & 0.808 & $0.05 \mathrm{I}$ & 15.860 & $* * *$ & $\mathrm{f}$ \\
(EIM) Crying & $0.95 \mathrm{I}$ & 0.056 & 17.117 & $* * *$ & $\mathrm{e}$ \\
(EIL) Worried face & 2.718 & 0.152 & 17.913 & $* * *$ & $\mathrm{~d}$ \\
(EIC) Repeat verb & 2.137 & 0.117 & 18.289 & $* * *$ & $\mathrm{c}$ \\
(EIN) Repeat moves & 2.216 & 0.121 & 18.277 & $* * *$ & $\mathrm{~b}$ \\
(E4DA) Dis behavior & $2.96 \mathrm{I}$ & 0.160 & 18.532 & $* * *$ & $\mathrm{a}$ \\
\hline
\end{tabular}

Note: ***Significantly different from zero at the 0.001 level (two-tailed). Abbreviations: $\mathrm{CR}$, critical ratio; $\mathrm{SE}$, standard error.
Table 10 Goodness of fit statistics for the measurement models

\begin{tabular}{lll}
\hline $\begin{array}{l}\text { Goodness of fit } \\
\text { statistics }\end{array}$ & $\begin{array}{l}\text { Stacked original } \\
\text { model }\end{array}$ & $\begin{array}{l}\text { Stacked revised } \\
\text { model }\end{array}$ \\
\hline$\chi^{2}$ & 30589.3 & 4933.4 \\
Degrees of freedom (df) & 249 & 143 \\
$P$ & 0.000 & 0.000 \\
Number of free & 63 & 77 \\
parameters & & \\
$\chi^{2} / d f$ & 122.849 & 34.45 \\
RMR & 0.024 & 0.011 \\
GFI & 0.887 & 0.981 \\
TLI & 0.820 & 0.965 \\
AGFI & 0.859 & 0.970 \\
RMSEA & 0.048 & 0.025 \\
Hoelter (0.05) & 500 & 1850
\end{tabular}

Abbreviations: AGFl, Adjusted Goodness of Fit Index; RMR, Root Mean Square Residual; GFI, Goodness of Fit Index; TLI, Tucker-Lewis Index. 
Table I I Goodness of fit statistical terms

\begin{tabular}{|c|c|}
\hline Goodness of fit statistics & Terms and understanding statistical output \\
\hline$\chi^{2}$ (chi-square) & $\begin{array}{l}\text { Best for models with sample sizes between } 75-100 \text {; for } n>100 \text { chi-square is almost always significant since } \\
\text { the magnitude is affected by the sample size; also affected by the size of correlations in the model, the larger } \\
\text { the correlations the poorer the fit }\end{array}$ \\
\hline Degrees of freedom (df) & $\begin{array}{l}\text { The number of degrees of freedom and equals } p-q \text { (the \# of sample moments subtract the \# of parameters } \\
\text { estimated) }\end{array}$ \\
\hline$P$ & $\begin{array}{l}\text { The probability is ideally non-significant; however, significant models can still yield valuable theoretical } \\
\text { construct information }\end{array}$ \\
\hline Number of free parameters & Multiple times 5-10 to estimate required sample size for the study \\
\hline$\chi^{2} / \mathrm{df}$ & $\begin{array}{l}\text { Use to compare models; this number should decrease from model to model; }<5 \text { is good, but must have } \\
P>0.05 \text {; close to } 1.0 \text { means it is a correct model }\end{array}$ \\
\hline RMR & $\begin{array}{l}\text { Root mean square residual is the square root of the average amount that the sample variances and covariances } \\
\text { differ from their estimates, smaller values are better }\end{array}$ \\
\hline GFI (also GOF) & $\begin{array}{l}\text { Slightly less than or equal }(0-I) \text { to I indicates a perfect fit; acceptable values are above } 0.90 \text {; affected by sample } \\
\text { size and can be large for poorly specified models }\end{array}$ \\
\hline TLI & The Tucker-Lewis coefficient should be between $0-I$, values close to I indicate a very good fit \\
\hline AGFI (also AGOF) & $\begin{array}{l}\text { Adjusted goodness of fit index, takes into account the } \mathrm{df} \text { available for testing the model; AGFI is bound by I, } \\
\text { which indicates a perfect fit; however is not bound by } 0\end{array}$ \\
\hline RMSEA & $\begin{array}{l}\text { Should be less than } 0.05 \text {; score of less than } 0.05 \text { indicates a close fit of the model in relation to the df. } \\
\text { Not definitive but the rule of thumb is an RMSEA of } 0.01 \text { is an exact fit, a score of } 0.08 \text { or less indicates a } \\
\text { reasonable error of approximation. A model with an RMSEA of greater than } 0.1 \text { should not be used - indicates } \\
\text { a poor fit }\end{array}$ \\
\hline Hoelter (0.05) & $\begin{array}{l}\text { The largest sample size for which one would accept the hypothesis that the model is correct; the index should } \\
\text { only be calculated if the chi-square is statistically significant. How small one's sample size would have to be for } \\
\text { chi-square to no longer be significant. Hoelter recommends values of at least } 200 \text {, values } \leq 75 \text { indicate a poor fit }\end{array}$ \\
\hline
\end{tabular}

Abbreviations: AGFI, adjusted goodness of fit index; AGOF, adjusted goodness of fit; GFI, goodness of fit index; GOF, goodness of fit; RMR, root mean square residual; RMSEA, root mean square error of approximation; TLI, tucker-lewis index.

and additional research to increase our understanding of pain behaviors and the effect of treatments on the elderly. The goal is improving pain control at all cognitive levels. ${ }^{22}$ Using existing data, we can target specific behaviors and evaluate outcomes to determine if uniformity of care is being applied across long-term care settings. In addition, when constructing federally required assessments, it is important to assess what standards are being applied in the use of key items as quality measures.

This study adds insight into additional domains/dimensions that can be used to improve pain assessment, and to re-evaluate efforts to detect pain and improve pain outcomes. Further evaluation of concomitance between pain and cognitive status longitudinally would provide an additional perspective on the long-term relationship between these two constructs. Future directions for research should include the persistence of pain behaviors. The MDS 2.0 contains alterability of selected behavioral items in section E4. Persistence of behaviors could indicate progression of the disease process, effectiveness of interventions to change behaviors, or an unknown factor in behavioral response to multiple stimuli.

Limitations of this study concern the data distribution. The data were positively skewed. Normality and equal group distribution were not assumed. Mahanalobis distance was not used to eliminate outliers, because the majority $(70 \%)$ of the population was initially reported as not experiencing pain and was not evenly distributed. Removing these cases would have removed a full spectrum of pain presentation of atypical symptoms of pain, ie, the target of the study. Previously published studies question the reliability of mood and behavioral sections from rater to rater when using the MDS. ${ }^{67,85}$ Further, the majority of residents needing skilled nursing care have some level of cognitive impairment, so intact groups were not proportionate to the mild, moderate, and severe cognitively impaired groups. This seminal work will build towards supporting change in current clinical practice, but additional clinical studies are needed to evaluate the assessment items as a clinical intervention from a translational research perspective.

\section{Conclusion}

A comprehensive plan for pain management should evaluate staffing patterns, staff education, and examine differences in pain policies and procedures to use pain management ultimately as a primary quality indicator in long-term care settings. ${ }^{86}$ Modeling theoretical constructs can serve as a valuable tool to determine the fit between clinical knowledge, the health care context, and individual needs. Additional research examining a covariance model of the relationship between 
pain and cognitive status over the long term could reveal if concomitant relationships exist. Evaluating covariance models, including antecedents and consequences of longterm suffering from unresolved pain, would further support the significance of understanding indicators and accurately assessing, documenting, and treating pain.

\section{Acknowledgments}

This research could not have been possible without the assistance of Seung Chun Paek, Research Associate of the Korean Health Insurance Corporation, Seoul, Korea, who ran the dataset parameters and queries. Thanks are extended to Steven Talbert and Diane Andrews, at the University of Central Florida, College of Nursing, for their reviews and edits of this manuscript. This research was completed at the University of Central Florida, College of Nursing in partnership with the College of Health and Public Affairs, Orlando, FL, and funded by the University of Central Florida Provost Fellowship.

\section{Disclosure}

The authors report no conflicts of interest in this work.

\section{References}

1. Epps CD. Recognizing pain in the institutionalized elder with dementia. Geriatr Nurs. 2001;22:71-79.

2. American Health Care Association. OSCAR data reports: Patient characteristics. Available at: http://www.ahca.org/research/oscar_patient. htm. Accessed April 15, 2006.

3. Lowe S. Census Bureau releases new data on residents of adult correctional facilities, nursing homes and other group quarters annual data also pain diverse portrait of nation's race, ethnic and ancestry group. Available at: http://www.census.gov/Press-Release/www/releases/ archives/american_community_survey_acs/010709.html. Accessed November 27, 2007.

4. Sawyer P, Lillis JP, Bodner EV, Allman R. Substantial daily pain among nursing home residents. J Am Med Dir Assoc. 2007;8:158-165.

5. Frondini C, Landfranchia G, Minardi M, Cucinotta D. Affective, behavior and cognitive disorders in the elderly with chronic musculoskeletal pain: the impact on an aging population. Arch Gerontol Geriatr. 2007;44:167-171.

6. Horgas AL, Elliot AF. Pain assessment and management in persons with dementia. Nurs Clin North Am. 2004;39:593-606.

7. Huffman JC, Kunik ME. Assessment and understanding of pain in patients with dementia. Gerontologist. 2000;40:574-581.

8. Balfour JE, O'Rourke N. Older adults with Alzheimer disease, co-morbid arthritis and prescription of psychotropic medications. Pain Res Manag. 2003;198:198-204.

9. Turk DC, Swanson KS, Tunks ER. Psychological approaches in the treatment of chronic pain patients - when pills, scalpels, and needles are not enough. Can J Psychiatry. 2008;53:213-223.

10. Davies E, Male M, Reimer V, Turner M. Pain assessment and cognitive impairment: part 2. Nurs Stand. 2004;19:33-40.

11. Davies E, Male M, Reimer V, Turner M, Wylie K. Pain assessment and cognitive impairment: part 1. Nurs Stand. 2004;19:39-42.

12. Benedetti F, Arduino C, Vighetti S, Asteggiano G, Tarenzi L, Rainero I. Pain reactivity in Alzheimer patients with different degrees of cognitive impairment and brain electrical activity deterioration. Pain. 2004;111: $22-29$.
13. Bachino C, Snow AL, Kunik ME, Cody M, Wristers K. Principles of pain assessment and treatment in non-communicative demented patients. Clin Gerontol. 2001;2:97-115.

14. Brignell A. Assessment of pain in non-cognizant elderly. Canadian Nursing Home. Feb/March 2003;14(1):71-74.

15. Cadogan MP. Assessing pain in cognitively impaired nursing home residents: the state of the science and the state we're in. J Am Med Dir Assoc. 2003;4:50-51.

16. Cavalieri TA. Pain management in the elderly. J Am Osteopath Assoc. 2002;102:481-485.

17. Miller LL, Talerico KA. Pain in older adults. Annu Rev Nurs Res. 2002;20:63-88.

18. Weiner DK, Rudy TE. Attitudinal barriers to effective treatment of persistent pain in nursing home residents. J Am Geriatr Soc. 2002;50:2035-2040.

19. Kovach CR, Logan BR, Noonan PE, et al. Effects of the serial trial intervention on discomfort and behavior of nursing home residents with dementia. Am J Alzheimers Dis Other Demen. 2006;21:147-155.

20. Horgas AL, Nichols AL, Schapson CA, Vietes K. Assessing pain in persons with dementia: Relationships among the non-communicative patient's pain assessment instrument, self-report, and behavioral observations. Pain Manag Nurs. 2007;8:77-85.

21. Cohen-Mansfield J. Pain assessment in noncommunicative elderly persons - PAINE. Clin J Pain. 2006;22:569-575.

22. Husebo BS, Strand LI, Moe-Nilssen R, Husebo SB, Aarsland D, Ljunggren AE. Who suffers most? Dementia and pain in nursing home patient's: a cross-sectional study. J Am Med Dir Assoc. 2008;9: 427-433.

23. Krulewitch H, London MR, Skakel VJ, Lundstedt GJ, Thomason H, Brummel-Smith K. assessment of pain in cognitively impaired older adults: a comparison of pain assessment tools and their use by nonprofessional caregivers. J Am Geriatr Soc. 2000;48:1607-1611.

24. Ryan J, Stone RI, Raynor CR. Using large data sets in long-term care to measure and improve quality. Nurs Outlook. 2004;52:38-44.

25. Arling G, Kane RL, Lewis T, Mueller C. Future development of nursing home quality indicators. Gerontologist. 2005;45:147-156.

26. Reichard J. Serious deficiencies found at almost one in every five nursing homes. Washington Health Policy. Available at: http://www. commonwealthfund.org/healthpolicyweek/healthpolicyweek_show. htm?doc_id=709233\&\#doc709237. Accessed on October 6, 2008.

27. JCAHO Joint Commission. Pain: Current understanding of assessment, management, and treatments. Available at: http://www.jcaho. org/news+room/health+care+issues/pain_mono_npc.pdf. Accessed January 16, 2006.

28. Acello B. Pain assessment in patients with dementia and how to use pain scales. Home Healthc Nurse. 2001;19:473-476.

29. American Health Quality Association. Improving quality of care in nursing homes. Fact sheet: Q10 success stories. Available at: http:// www.ahqa.org/pub/media/159_766_3906.cfm. Accessed January 20, 2006.

30. Leong IY, Farrell MJ, Helme RD, Gibson SJ. The relationship between medical comorbidity and self-rated pain, mood disturbance, and function in older people with chronic pain. J Gerontol B Biol Sci Med Sci. 2007;62A:550-555.

31. Cohen-Mansfield J, Creedon M. Nursing staff member's perceptions of pain indicators in persons with severe dementia. Clin J Pain. 2002;18:64-73.

32. Warren J, Bolton P. Data mining for on-line support of general practice. Top Health Inf Manage. 2001;22:51-64.

33. Helme RD, Gibson SJ. The epidemiology of pain in elderly people. Clin Geriatr Med. 2001;17:417-431.

34. Fordyce WE. Pain and suffering: a reappraisal. Am Psychol. 1988;43: 276-283.

35. Fordyce WE. A behavioral perspective on chronic pain. Br J Clin Psychol. 1982;21:313-320.

36. Fordyce WE. Pain measurement and pain behavior. Pain. 1984;18: $53-69$. 
37. Turk DC, Wack JT, Kerns RD. An empirical examination of the "painbehavior" construct. J Behav Med. 1985;892:119-130.

38. Buffum MD, Hutt E, Chang VT, Craine MH, Snow AL. Cognitive impairment and pain management: Review of issues and challenges. J Rehabil Res Dev. 2007;44:315-329.

39. Algase DL, Beck C, Kolanowski A, et al. Need-driven dementiacompromised behavior: An alternative view of disruptive behavior. Am J Alzheimers Dis Other Demen.1996;11:12-19.

40. Ratner C. A social constructionist critique of naturalistic theories of emotion. Journal of Mind and Behavior. 1989;10:211-230. Available at: http://www.humboldt1.com/ cr2/emotions.htm. Accessed November 13, 2008

41. Fordyce WE. Evaluating and managing chronic pain. Geriatrics. 1978;33:59-62.

42. Gureje O, Korff MV, Kola L, et al. The relation between multiple pains and mental disorders: results from the World Mental Health surveys. Pain. 2008;135:82-91.

43. Shega JW, Rudy T, Keefe FJ, Perri LC, Mengin OT, Weiner DK. Validity of pain behaviors in persons with mild to moderate cognitive impairment. J Am Geriatr Soc. 2008;56:1631-1637.

44. Lints-Martindale AC, Hadjistavropoulos T, Barber B, Gibson SJ. A psychophysical investigation of the facial action coding system as an index of pain variability among older adults with and without Alzheimer's Disease. Pain Med. 2007;8:678-689.

45. Kunz M, Scharmann S, Hemmeter U, Schepelmann K, Lautenbacher S. The facial expression of pain in patients with dementia. Pain. 2008;133: 221-228.

46. Thibault P, Loisel P, Durand M-J, Catchlove R, Sullivan MJL. Psychological predictors of pain expression and activity intolerance in chronic pain patients. Pain. 2008;139:47-54.

47. Horgas AL. Assessing pain in persons with dementia. Medsurg Nurs. 2007;16:207-208.

48. Kaasalainen S, Coker E, Dolovich L, et al. Pain management decisions making among long-term care physicians and nurses. West J Nurs Res. 2007;29:561-580.

49. Hurley AC, Volicer BJ, Hanrahan PA, Houde S, Volicer L. Assessment of discomfort in advanced Alzheimer patients. Res Nurs Health. 1992;15:369-377.

50. Oh H, Eom M, Kwon Y. A study on aggressive behavior among nursing home residents with cognitive impairment. Taehan Kanho Hakhoe Chi. 2004;34:1541-1459. Korean.

51. Kolanowski AM, Garr M. Relation of premorbid factors to aggressive physical behavior in dementia. J Neurosci Nurs. 1999;31:278-284.

52. Kamaleri Y, Natvig B, Ihlebaek CM, Benth JS, Bruusgaard D. Change in the number of musculoskeletal pain sites: a 14-year prospective study. Pain. 2009;141:25-30.

53. Pautex S, Michon A, Guedira M, et al. Pain in severe dementia: self-assessment or observational scales? J Am Geriatr Soc. 2006;54: 1040-1045

54. Fisher SE, Burgio LD, Thorn BE, Hardin JM. Obtaining self-report data from cognitively impaired elders: methodological issues and clinical implications for nursing home pain assessment. Gerontologist. 2006;46: 81-88.

55. Murdoch J, Larsen D. Assessing pain in cognitively impaired older adults. Nurs Stand. 2004;18:33-39.

56. Kovach CR, Noonan PE, Schlidt AM, Wells T. A model of consequences of need-driven, dementia-compromised behavior. $J$ Nurs Scholarsh. 2005;37:134-140.

57. Penrod J, Yu F, Kolanowski A, Fick DM, Loeb SJ, Hupcey JE. Reframing person-centered nursing care for persons with dementia. Res Theory Nurs Pract. 2007;21:57-72.

58. Colling KB. Passive behaviors in dementia: clinical application of the need-driven dementia-compromised behavior model. J Gerontol Nurs. 1999;25:27-32.

59. Mitty E, Flores S. Assisted living nursing practice: the language of dementia: theories and interventions. Geriatr Nurs. 2007;28: 283-288.
60. Kolanowski A, Litaker M, Buettner L. Efficacy of theory-based activities for behavioral symptoms of dementia. Nurs Res. 2005;54:219-228.

61. Colling KB, Buettner L. Simple pleasures: interventions from the need-driven dementia-compromised behavior model. J Gerontol Nurs. 2002;28:10-19.

62. Ellis J. [Commentary] A model of consequences of need-driven, dementia-compromised behavior. J Nurs Scholarsh. 2005;37(2):140.

63. Centers for Medicare and Medicaid Services. MDS 2.0 for Nursing Homes. CMS Available at: http://www.cms.hhs.gov/ NursingHomeQualityInits/20_NHQIMDS20.asp. Accessed June 23, 2008.

64. Won A, Morris JN, Nonemaker S, Lipsitz LA. A foundation for excellence in long-term care: the minimum data set. Ann Longterm Care. 1999;7:92-97.

65. Snowden M, McCormick W, Russo J, et al. Validity and responsiveness of the minimum data set. J Am Geriatr Soc. 1999;35:172-178.

66. Lawton MP, Casten R, Parmelee PA, Van Haitsma K, Corn J, Kleban MH. Psychometric characteristics of the Minimum Data Set II: Validity. J Am Geriatr Soc. 1998;46:736-744.

67. Hawes C, Morris JN, Phillips CD, Mor V, Fries BE, Nonemaker S. Reliability estimates for the minimum data set for nursing home resident assessment and care screening (MDS). Gerontologist. 1995;35: 172-178.

68. Morris JN, Fries BE, Mehr DR, et al. MDS Cognitive Performance Scale. J Gerontol. 1994;49:M174-M182.

69. Fries BE. New opportunities for research in cognitive aging: the National Nursing Home Resident Assessment Instrument. Division 20 American Psychological Association. University of Michigan. Available at: http://apadiv20.phhp.ufl.edu/fries.htm. Accessed June 12, 2008.

70. Gruber-Baldini AL, Zimmerman SI, Mortimore E, Magaziner J. The validity of the minimum data set in measuring the cognitive impairment of persons admitted to nursing homes. J Am Geriatr Soc. 2000;48:1601-1606.

71. Folstein MF, Folstein SE, McHugh PR. Mini-mental state: a practical method for grading the cognitive state of patients for the clinician. J Psychiatr Res. 1975;12:189-198.

72. Carpenter GI, Hastie CL, Morris JN, Fries BE, Ankri J. Measuring change in activities of daily living in nursing home residents with moderate to severe cognitive impairment. BMC Geriatr. Available at: http://www.biomedcentral.com/1471-2318/6/7. Accessed October 18, 2006.

73. Fries BE, Simon SE, Morris JN, Flodstrom C, Bookstein FL. Pain in U.S. nursing homes: Validating a pain scale for the Minimum Data Set. Gerontologist. 2001;41:173-179.

74. Kaplan D. Statistical power in structural equation models. Department of Educational Studies, University of Delaware. Available at: http:// www2.gsu.edu/ mkteer/power.html. Accessed October 21, 2008.

75. Cipher D, Clifford PA, Roper KD. Behavioral manifestations of pain in the demented elderly. J Am Med Dir Assoc. 2006;7: 355-365.

76. Zanocchi M, Maero B, Nicola E, et al. Chronic pain in a sample of nursing home residents: prevalence, characteristics, influence on quality of life (QOL). Arch Gerontol Geriatr. 2008;47:121-128.

77. Reynolds KS, Hanson LC, DeVellis RF, Henderson M, Steinhauser KE. Disparities in pain management between cognitively intact and cognitively impaired nursing home residents. J Pain Symptom Manage. 2008;35:388-396.

78. Leong IY, Nuo TH. Prevalence of pain in nursing home residents with different cognitive and communicative abilities. Clin J Pain. 2007;23:119-127.

79. Nygaard HA, Jarland M. Are nursing home patients with dementia diagnosis at increased risk for inadequate pain treatment? Int $J$ Geriatr Psychiatry. 2005;20:730-737.

80. Snow AL, O'Malley KJ, Cody M, et al. A conceptual model of pain assessment for noncommunicative persons with dementia. Gerontologist. 2004;44:807-817. 
81. Ruzicka S, Sanchez-Reily S, Meghan G. Holistic assessment of chronic pain among elders. Am J Hosp Palliat Med. 2007;24:291-299.

82. Iezzi T, Duckworth MP, Vuong LN, Archibald YM, Klinck A. Predictors of neurocognitive performance in chronic pain patients. Int J Behav Med. 2004;11:56-61.

83. Magee T, Lee SM, Giuliano KK, Munro B. Generating new knowledge from existing data: The use of large data sets for nursing residents. Nurs Res. 2006;55:S50-S56.

84. Blyth FM. Chronic pain - is it a public health problem? Pain. 2008;137: 465-466.
85. Casten R, Lawton MP, Parmelee PA, Kleban MH. Psychometric characteristics of the minimum data set I: confirmatory factor analysis J Am Geriatr Soc. 1998;46:726-735.

86. Keeney CE, Scharfenberger JA, O’Brien JG, Looney S, Pfeifer MP, Hermann CP. Initiating and sustaining a standardized pain management program in long-term care facilities. J Am Med Dir Assoc. 2008;9:347-353.

\section{Publish your work in this journal}

Clinical Interventions in Aging is an international, peer-reviewed journal focusing on evidence-based reports on the value or lack thereof of treatments intended to prevent or delay the onset of maladaptive correlates of aging in human beings. This journal is indexed on PubMed Central, MedLine, the American Chemical Society's 'Chemical Abstracts Ser-

\section{Dovepress}

vice' (CAS), Scopus and the Elsevier Bibliographic databases. The manuscript management system is completely online and includes a very quick and fair peer-review system, which is all easy to use. Visit http://www.dovepress.com/testimonials.php to read real quotes from published authors.

Submit your manuscript here: http://www.dovepress.com/clinical-interventions-in-aging-journal 